\title{
Design and explanation of organizational excellence model in home appliances industry
}

\author{
Seyed Abbas Kazemi ${ }^{a}$, Gholamhossein Nikokar ${ }^{a}$, Jamshid Salehi Sadaghiani ${ }^{\mathrm{b}}$ and Majid \\ Rahimimazraehshahi $^{\mathbf{a}^{*}}$
}

${ }^{a}$ Department of Management, Imam Hossein University, Tehran, Iran

${ }^{b}$ Department of Management, Allameh Tabatabae University, Tehran, Iran

\begin{tabular}{l}
\hline A R T I C L E I N F O \\
\hline Article history: \\
Received March 1, 2011 \\
Received in Revised form \\
July, 14, 2011 \\
Accepted 15 July 2011 \\
Available online \\
17 July 2011 \\
\hline Keywords: \\
Home appliances \\
Organizational excellence \\
EFQM \\
TQM \\
LISREL
\end{tabular}

A B S T R A C T

\begin{abstract}
Home appliances are considered as one of low margin and competitive industry in the world. This industry often needs significant amount of investment and resources and it often faces with some challenges during economic crises. In this paper, we present a framework for organizational excellence to detect any possible problems in home appliances industry. The proposed framework of this paper is used for a real-world case study of Iranian home appliances. The results of our survey indicate that there are four major dimensions involved with this industry including facilities, knowledge and skills, environment and vision. There are three criteria associated with facilities with 30 indexes, 14 criteria associated with knowledge and skills with 144 indexes, three criteria involved with environment with 33 indexes and five criteria linked with vision with 53 indexes. Therefore, home appliances in our case study needs 4 dimensions for achieving the organizational excellence.
\end{abstract}

(C) 2012 Growing Science Ltd. All rights reserved.

\section{Introduction}

The new millennium started with a wave of many economic crises from infamous incident of September 11 to financial crises of real state. The tsunami of these events distributed in almost all countries worldwide. Many people lost their jobs and world economy has gone under tremendous pressure. In such shrinking economy, people may prefer not replace their durable goods such as home appliances in an attempt to save more and survive. Therefore, we may expect to see a more challenging environment for home appliances producers. As a result, there is a need to find the most important issues affecting this kind of businesses and provide possible changes on the industry to survive. Business excellence is the systematic use of quality management rules and methods in business management, with the aim of improving performance based on the principles of customer concentration, stakeholder value, and process management.

There are various methods for organizational excellence to detect weakness and strength in home appliances industry. Deming $(1986,2000)$ is believed as one of the most important models for

* Corresponding author. Tel. + 989121017754

E-mail addresses: rahimi@iranpouya.com (M. Rahimimazraehshahi) 
assessing organizational excellence. Deming, in his model, emphasizes four issues for improving business issues, which are as follows,

1. Appreciation of a system: understanding the overall processes including suppliers, producers, and customers of goods and services,

2. Knowledge of variation: the range and causes of differentiation in quality, and use of statistical sampling in measurements,

3. Theory of knowledge: the ideas of explaining knowledge and the limits of what can be known,

4. Knowledge of psychology: concepts of human nature.

Deming specify 14 step key principles for management of transforming businesses into effectiveness units and the interested readers are referred to read Deming (1986) for more details on Deming's models. The appreciation of a system involves understanding how feedbacks between the elements of a system yield in internal restrictions, which forces the system to behave as a single organism. The knowledge of variation is to understand that everything measured is a combination of both normal variations due to the flexibility of the system and of special causes that create defects. Deming's system has been widely used in the world and it has been considered as one of the most important organizational excellence.

Business excellence, as described by the European foundation for quality management (EFQM), refers to "outstanding practices in managing the organization and achieving results, all based on a set of eight fundamental concepts." These concepts are orientation on balanced results, focus on customer value, leadership and constancy of purpose, management by processes and facts, people development and involvement including continuous learning, innovation and improvement, partnership development and public responsibility (Link \& Scott, 2001; Hakes, 2007).

Saizarbitoria et al. (2006) analyzed the influence on European companies' performance of the two most popular models for quality management (QM) practice, which are the ISO 9000 and the EFQM. In their method, they used a qualitative survey carried out in Spain using the Delphi method, based on previous research work and they analyzed the results and compared with the results of other surveys carried out previously, as well as with information gathered during several in-depth interviews of the experts that participated in their Delphi panel (Linstone, \& Turoff, 2002). They reported that the panel of experts, the implementation of QM models in the studied region had a positive influence on company results, mainly through the improvement of operations, efficiency and the costs of companies' internal activities. Casadesús et al. (2001) discussed the effects of the implementation of ISO9000 for many industries located in Spain. Gotzamani and Tsiotras (2002) explained the true motives behind ISO 9000 certification.

The proposed study of this paper presents a new framework of business excellences for home appliances industry. This organization of this paper first present the framework of the work in section 2 and details of our survey is presented in section 3. Finally, concluding remarks are given to summarize the contribution of the paper.

\section{The proposed framework}

The proposed framework of our study has four dimensions of facilities, knowledge, skill and vision and environment. There is a correlation among these components and we study the details of these items. Fig. 1 shows the relationships among these dimensions. As we can observe from Fig 1, different aspects of management affect business excellences such as economical, social \& culture, politics, etc. These factors are some other internal factors, which affect the business such as knowledge and skills, facilities and visions. 


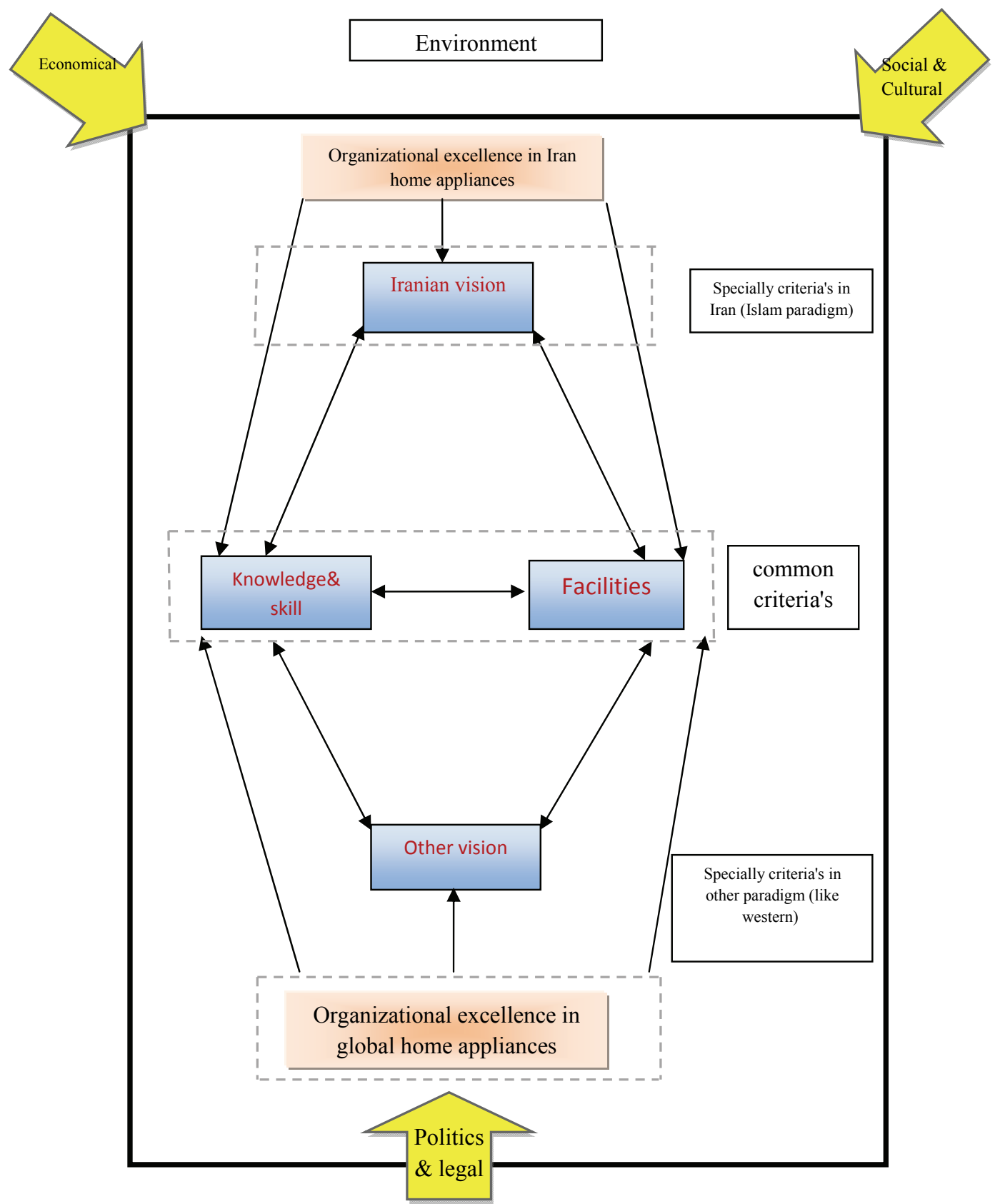

Fig. 1. The structure of the framework

The proposed framework of this paper has been used for home appliances of Iranian industries and the results have been analyzed using LISREL software package. The proposed model has been based on questionnaire consists of different questions and the relationship among dimensions and criteria have also been studied. We have used various methods to gather the necessary information such as Library study from scientific article, dissertation, Islamic resources, annual report analysis from reliable home appliances in the world, review of scientist's idea, survey method, etc. The data gathered from different resources are gathered using three different techniques of observation questionnaire and interview. In this paper, we have used confirmatory analysis factor (CAF) to validate the results. The reliability of the survey has been performed using twenty samples from Cronbach alpha (1951) coefficient, which yielded 0.989, and it is well above 0.7 of an acceptable level. The population of this survey includes the entire organizational excellence scientists in Iran 
who are familiar with home appliances industry. The study was performed during a 4-year-period from 2007 to 2011. Confirmatory factor analysis and structural equation method have been used for data analysis and hypothesis test for correlation between variant have been implemented using Pearson correlation coefficient. Analysis of population universe and pilot study are used as descriptive statistics.

\section{The results}

The main question of this survey is to determine the appropriate excellent model for home appliance industry in Iran and Fig. 2 provides some responses for this question.

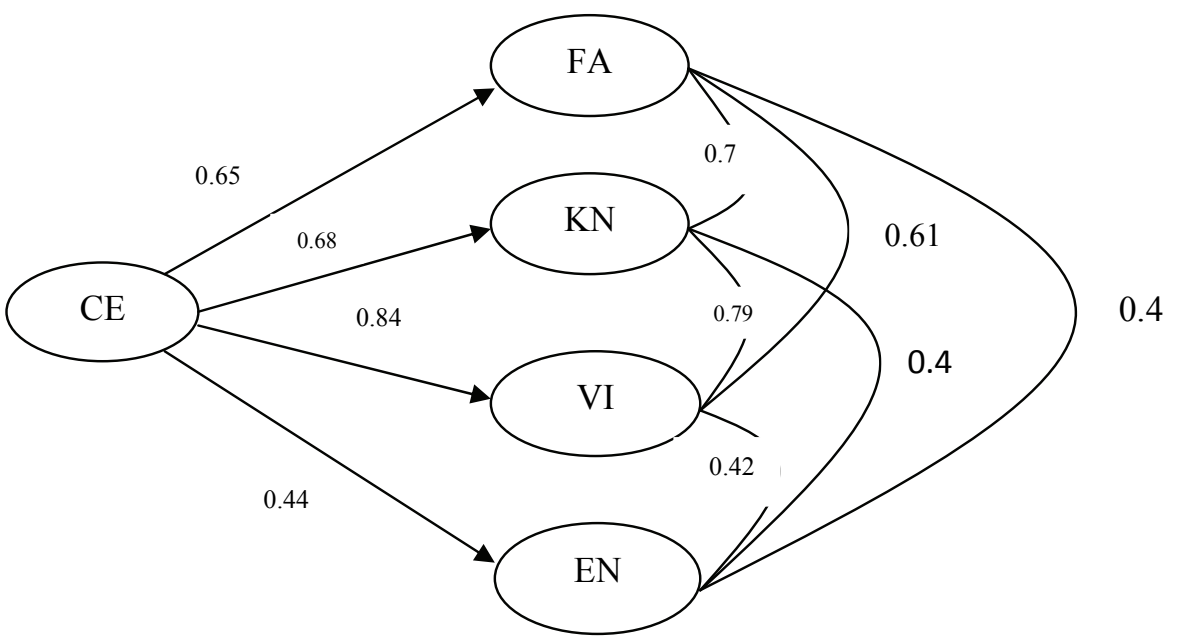

Fig. 2. The results of organizational excellence

In Fig. 2, FA, KN, VI and EN represent the facilities, knowledge and skills, vision and environment, respectively. The correlation coeffcients among all four dimensions are summarized in Table 1 as follows,

\section{Table 1}

The correlation numbers for four dimensions

\begin{tabular}{lcccc}
\hline Dimensions & 1 & 2 & 3 & 4 \\
\hline Facilities (FA) & 1 & & & \\
Knowledge \& Skills(KN) & $0.704^{*}$ & 1 & 1 & \\
Vision (V) & $0.612^{*}$ & $0.796^{*}$ & $0.424^{*}$ & 1 \\
Environment (EV) & $0.401^{*}$ & $0.408^{*}$ & \\
\hline
\end{tabular}

${ }^{*} \mathrm{p}<.01$

Table 2 summarizes the results of the dimensions and mean weights of four items.

\section{Table 2}

The mean weights for four dimensions

\begin{tabular}{lcc}
\hline Dimensions & Dimension & Mean weight \\
\hline Facilities (FA) & 25.8 & 258 \\
Knowledge \& Skills(KN) & 25.8 & 258 \\
Vision (V) & 24.3 & 243 \\
Environment (EV) & 24.1 & 241 \\
\hline Sum & 100 & 1000 \\
\hline
\end{tabular}

Table 3 shows the results of the dimensions and mean weights for facilities. 
Table 3

The mean weights for facilities

\begin{tabular}{lcc}
\hline Dimensions & Dimension & Mean weight \\
\hline Purchase \& material supply chain & 33.3 & 86 \\
Capital \& money & 33.3 & 86 \\
Machinery \& equipment & 33.3 & 86 \\
\hline Sum & 100 & 258 \\
\hline
\end{tabular}

Table 4, 5 and 6 shows the results of the dimensions and mean weights for knowledge and skills, vision and environment, respectively.

\section{Table 4}

The mean weights for knowledge and skills

\begin{tabular}{lcc}
\hline Dimensions & Dimension & Mean weight \\
\hline Leadership & 7.5 & 18 \\
Technology management \& Research \& development & 7.5 & 18 \\
Innovation & 7.5 & 18 \\
Customer oriented & 7.5 & 18 \\
Human resourced management & 7.5 & 18 \\
Process management & 7.5 & 18 \\
Results & 7 & 17 \\
Learning \& training & 7 & 17 \\
Management information system & 7 & 17 \\
Structure & 7.5 & 18 \\
Policy & 7.5 & 18 \\
Culture & 6.5 & 17 \\
Contractors & 6.5 & 17 \\
Society and responsibility of society & 5.5 & 14 \\
\hline Sum & 100 & 243 \\
\hline
\end{tabular}

\section{Table 5}

The mean weights for vision

\begin{tabular}{lcc}
\hline Dimensions & Dimension & Mean weight \\
\hline Ethic \& behavior of leadership & 20 & 48 \\
Polite \& make self of employee & 17 & 40 \\
Social and favorite relationship & 22 & 53 \\
Islam oriented attitudes & 21 & 52 \\
Self assessment & 20 & 48 \\
\hline Sum & 100 & 241 \\
\hline
\end{tabular}

Table 6

The mean weights for environment

\begin{tabular}{lcc}
\hline Dimensions & Dimension & Mean weight \\
\hline Ethic \& behavior of leadership & 20 & 48 \\
Polite \& make self of employee & 17 & 40 \\
Social and favorite relationship & 22 & 53 \\
Islam oriented attitudes & 21 & 52 \\
Self assessment & 20 & 48 \\
\hline Sum & 100 & 241 \\
\hline
\end{tabular}

Now the question is how to achieve the organizational excellence in Iran home appliances industry and we believe the following comments could help this industry cope with the current challenges in the industry. In terms of machinery criteria, this industry should buy flexible low energy consumption and purchase criteria should be evaluated of contractor just in time \& use of new sources to reduce 
the cost of production and increase profit. In terms of knowledge and skills, we must improve distribution and recognition of customers in market, perform research in variety of customer relationship management $\&$ assessment of customer. Management $\&$ leadership must improvement their management skills and they must create new opportunities based on creativity and innovention. Technology and research must be under appropriate budegeting program and a good communication with the society must be performed. The firms must be under continous communication with their partners to covey their experience and awareness on the ongoing changes of the events. Human resources management criteria must have partnership, motivation \& courage and punishment to increase productivity. Partners must have relationship with their internal and external units to increase the quality. Culture criteria must perform activity in discipline and commitment \& royalty, passion in action reaction and assertiveness in decision.

In terms of vision, ethic \& behavior of leadership must incorporate equity and patience, consultant, humanity and attention to humanity. The employee must be polite reflect a good image for the firm according to Islamic training and ethics. Social and favorite relationship must establish a team work in the context of technical and cultural for achieving physical and spiritual goals. All activities must be in accordance with Islam's sharie promoting ethical rules among society. Self assessment criteria must control people's behaviors and activities. Finally, in terms of environment dimensions, government must be enouraged to reduce interest rates as much as possible in an attempt to help reduce the cost of borrowing and increase the chance of low financing.

\section{Conclusions}

In this paper, we have presented a framework for organizational excellence to address all challenges in home appliances industry. The proposed framework of this paper was used for a real-world case study of Iranian home appliances. The results of our survey indicated that there were four major dimensions involved with this industry including facilities, knowledge and skills, environment and vision. We have anaylzed all relative challenges and addressed any possible guidelines to help this industry grow. We hope the results of this survey could be used for other researchers to improve other sectors of industries.

\section{References}

Casadesús, M., Gimenez, G., \& Heras, I. (2001). Benefits of the ISO 9000 implementation in Spanish industry. European Business Review, 13(6), 327-35.

Cronbach, L. J. (1951). Coefficient alpha and the internal structure of tests. Psychometrika, 16(3), 297-334.

Gotzamani, K.D., \& Tsiotras, G.D. (2002). The true motives behind ISO 9000 certification. International Journal of Quality \& Reliability Management, 19(2), 151-69.

Deming, W. E. (1986). Out of the Crisis. MIT Press. ISBN 0-911379-01-0.

Deming, W. E.(2000). The New Economics for Industry, Government, Education (2nd ed.). MIT Press. ISBN 0-262-54116-5.

Hakes, C. (2007). The EFQM Excellence Model: For Assessing Organizational Performance - A Management Guide. Van Haren Publishing, ISBN 978-90-8753-027-3.

Linstone, A., \& Turoff, M. (2002). The Delphi Method: Technique and Applications. e-book, available at: www.is.njit.edu/pubs/delphibook/.

Likert, R. (1932). A Technique for the Measurement of Attitudes. Archives of Psychology, 140, 1-55.

Link, A.N., \& J.T. Scott (2001). Economic Evaluation of the Baldrige National Quality Program. National Institute of Science and Technology, US Department of Commerce.

Saizarbitoria, I. H., Landín, G. A., \& Fa, M. C. (2006). The impact of quality management in European companies' performance: The case of the Spanish companies. European Business Review, 18(2), 114-131. 